\title{
Antibiotics prescription for febrile patients: associated factors in a health facility-based survey in the Greater Accra region of Ghana
}

\section{Michael Mireku Opoku}

University of Ghana School of Public Health

Harriet Affran Bonful ( $\square$ harriet.bonful@gcpharm.edu.gh )

Ghana College of Pharmacists https://orcid.org/0000-0003-0069-3241

Kwadwo Ansah Koram

University of Ghana Noguchi Memorial Institute for Medical Research

Research article

Keywords: Predictors, Antibiotic Prescription, febrile, facility-based, Ghana

Posted Date: December 4th, 2019

DOI: https://doi.org/10.21203/rs.2.10739/v2

License: (c) (i) This work is licensed under a Creative Commons Attribution 4.0 International License.

Read Full License 


\section{Abstract}

Introduction: Frequent and/or misguided prescription of antibiotics are important facilitators of the emergence and spread of antibiotic resistance. In the absence of the implementation of effective interventions to control antibiotic use, its consumption may increase out of proportion to requirements. Antibiotic stewardship interventions must be appropriately targeted and assessed to enhance the proper use of antibiotics. The objective of this study was to determine the factors associated with of antibiotics prescription to febrile patients who seek care in health facilities within the Greater Accra region of Ghana.

Methods: Secondary data obtained from a review of medical records of 2,519 febrile patients at the outpatient department of 6 health facilities in 3 municipalities during the baseline survey of a quasiexperiment in 2016 were used. The primary outcome was prescription of any antibiotic. Independent variables included patients' demographics, symptoms, laboratory investigations (blood film microscopy, malaria rapid diagnostic test, full blood count, urine and stool routine examinations), diagnoses, and prescribers' demographics. Crude and adjusted logistic regression analyses were used to determine the factors associated with antibiotics prescription.

Results: The prevalence of antibiotics prescription was 70.1\% (95\% Cl: 67.7-72.4). Prescribers with more years of practice (>5years) were more likely to prescribe antibiotics compared to those with less than 3 years of practice $(p<0.001)$. Integrated Management of Neonatal and Childhood Illnesses (IMNCI) training was associated with a $2.3(95 \% \mathrm{Cl}: 1.54,3.53, \mathrm{p}<0.001)$ times higher odds of antibiotic prescribing. Patients aged 5 years or more were $60 \%$ less likely to be prescribed antibiotics compared with those under 5 years $(A O R=0.40,95 \% \mathrm{Cl}: 0.32,0.51 ; p<0.001)$. Patients referred for laboratory investigations were $29 \%$ less likely to be prescribed with antibiotics than those not referred. Presenting to the outpatient clinic with cough was associated with a 3.5 (95\% Cl: $2.54,4.92)$ times higher odds of antibiotics prescribing.

Conclusion: Prescription of antibiotics to febrile patients was high. Promoting laboratory testing can potentially reduce irrational antibiotics prescribing. Prescribing antibiotics for children under five and the prescribing practices of prescribers with longer years of practice should be targeted with interventions to reduce high use of antibiotics.

\section{Introduction}

Antibiotic resistance is a major global health challenge. Frequent or misguided consumption of antibiotics are critically important facilitators of the emergence and spread of antibiotic resistance [1, 2]. Higher consumption is not only associated with antibiotic resistance at the individual level but also at the community, national and regional levels, with implications for all patients [2]. A study of the global consumption pattern of antibiotics found that antibiotic consumption increased by $65 \%$ between 2000 and 2015 [3]. This study further estimates that antibiotic consumption will increase out of proportion to requirements by 2030 , if no new policy interventions are implemented. 
Developing countries contribute disproportionately more to the increasing trend of antibiotic consumption than developed countries [3-5]. Owing to the poor availability of data, antibiotic use in these countries is not optimally understood [5]. In African communities, high and inappropriate use of antibiotics have been shown to be widespread [6-8]. The prevalence of antibiotics prescription in selected hospitals across Africa has been estimated to be $50 \%$ [8]. This is the highest of all the WHO regions. A comparable point prevalence (51.4\%) was determined by an antibiotic-use-survey at a teaching hospital in Ghana [9]. Inappropriate prescription of antibiotics has also been established among prescribers in other parts of Ghana $[10,11]$. The phenomenon is driven by patients' demands, poor quality laboratory services, pressure from pharmaceutical companies' promotional activities, and health worker factors such as nonadherence and lack of access to institutional guidelines and also poor knowledge [12, 13].

Interventions which have been introduced to reduce irrational prescription of antibiotics in Ghana include the Standard Treatment Guidelines (STG) and Essential Medicines List (EML), provision of training and supervision for health care providers and mass education of the public [14]. To ensure rational use of antibiotics and delay potential development of antimicrobial resistance, the Ghana National Policy on antimicrobial use and resistance has been introduced [15].

For these interventions to be successful, the determinants of the prevailing undesirable patterns of antibiotic use need to be identified and appropriately targeted in local antibiotic stewardship education [16]. In the long run, these activities should lead to a reduction in the rate of emergence of bacterial resistance, hospital visits, medical costs and the incidence of side effects $[17,18]$. The knowledge gained will be key to informing the policy changes necessary for reversing the increasing trend of antibiotic consumption at all levels.

To these ends, the objective of this study was to determine the factors associated with prescription of antibiotics for febrile patients who sought care in health facilities within the Greater Accra region of Ghana using data from the last quarter of 2015.

\section{Methods}

Study area

Data for this study were obtained from the baseline survey of a quasi-experimental study, which sought to develop and assess the effectiveness of a one-way text messaging intervention on health providers' adherence to malaria case management guidelines [19]. The study was conducted in Ga South, La DadeKotopon and La-Nkwantanang Madina municipalities in the Greater Accra region from October to December 2015. The cross-sectional survey collected data in 6 health facilities, 2 in each of the 3 municipalities. As at the time of the study, Greater Accra was one of 10 administrative regions in Ghana with 16 administrative units (including municipalities).

Data collection 
The secondary data contained the medical records of 2,519 febrile patients who were neither detained for observation nor admitted on the ward but treated on ambulatory basis at the out-patient department (OPD) of the six health facilities. Records of patients who were pregnant and patients who attended for review of a previous illness were excluded.

Data extraction tools were used to collect data from patients' records in the primary study. Being febrile was defined as having a recorded body temperature of $37.5^{\circ} \mathrm{C}$ or more and/or having fever recorded in clinical notes on a survey day. All eligible patients during the survey period (October to December 2015) were sampled. The data extraction tool for patients captured information on demographic characteristics, presenting symptoms, laboratory investigations requested (including blood film microscopy or malaria rapid diagnostic test, full blood count (FBC), stool examination for parasitic infections (stool routine examination) and simple urine examination for protein and haematuria (urine routine examination), diagnoses and all prescribed drugs including information on the dosage regimen. Further to that, the 82 prescribers who saw the patients on the visits selected for inclusion in the study were interviewed using a structured questionnaire. This questionnaire was designed to capture information on prescribers' demographics, exposure to in-service training on Malaria case management (MCM) and integrated management of neonatal and childhood illnesses $(\mathrm{IMNCI})$, access to guidelines or other reference materials on $\mathrm{MCM}$, and exposure to supervision in the past six months. Details on the data extraction tools and detailed methodology of the primary study has been published elsewhere [19].

Data management and analysis

The data obtained were validated and analysed using Stata Version 14 [20]. For the purposes of this study diagnoses of interest was defined as all diagnoses which had a prevalence of at least $5 \%$ in the database. The outcome variable, prescription of antibiotics, was derived based on whether or not at least 1 antibiotic was prescribed for the patient. A prescribed medicine was considered an antibiotic if it was so classified by the WHO Anatomical Therapeutic Chemical classification, J01 (Antibacterials for systemic use) and P01AB (nitroimidazole derivatives) [21]. The distribution of categorical variables such as sex, the presenting symptoms, the diagnoses and laboratory investigations were assessed using frequencies. For continuous variables such as age, normality was assessed using histograms. To adjust for clustering, unique identifiers for each patient folder and for the municipalities were chosen as primary sampling units and stratum identifiers, respectively. Simple logistic regression analyses were used to estimate unadjusted odds ratios for all the independent variables. The variables which were significantly associated with antibiotic prescribing $(p<0.05)$ were used to fit a multivariable logistic regression model. Although sex of patient was not significant in the crude analysis it was included in the adjusted model because it was considered a potential confounder. The factors in the adjusted model were checked for multicollinearity using the "collin" command in Stata 14. Adjusted Wald test was used to determine the significance of multilevel categorical variables in the model. Cluster-Robust standard errors were estimated for all models. Statistical significance was set at $p<0.05$.

\section{Results}


A total of 2,519 valid records of patients, who had received care at the selected health facilities in Accra, were used for the study. Patient and facility level descriptive characteristics are presented (Table 1). Of patients prescribed with antibiotics, 4 out of 10 were aged above 5 years. It must be noted that $1.2 \%$ of the folders did not have age recorded in them. The proportion of females prescribed with antibiotics was $51.9 \%$. Regarding registration with the main social health insurance scheme in Ghana, the national health insurance scheme (NHIS) or other schemes, $57.6 \%$ of patients were registered.

Table 1: Facility and patient level descriptive characteristics by antibiotic prescription

\begin{tabular}{|c|c|c|c|c|c|c|}
\hline & \multicolumn{6}{|c|}{ Antibiotics prescription } \\
\hline & \multicolumn{2}{|c|}{ Not Prescribed } & \multicolumn{2}{|c|}{ Prescribed } & \multicolumn{2}{|c|}{ Total, $\mathrm{N}=2,519$} \\
\hline & $\mathbf{n}$ & $\%^{\mathrm{a}}$ & $\mathbf{n}$ & $\%^{\mathrm{a}}$ & $\mathbf{n}$ & $\%^{\mathrm{b}}$ \\
\hline \multicolumn{7}{|l|}{ Municipality } \\
\hline \multicolumn{7}{|l|}{ Ga South $(N=811)$} \\
\hline Ga South Municipal Hospital & 148 & 74.7 & 430 & 70.1 & 578 & 71.3 \\
\hline Ngleshie Amanfrom Health Centre & 50 & 25.3 & 183 & 29.9 & 233 & 28.7 \\
\hline \multicolumn{7}{|l|}{ La Dade Kotopon $(\mathrm{N}=802)$} \\
\hline La General Hospital & 78 & 35.5 & 215 & 36.9 & 293 & 36.5 \\
\hline Police Hospital & 142 & 64.5 & 367 & 63.1 & 509 & 63.5 \\
\hline \multicolumn{7}{|l|}{ La Nkwantanang Madina ( $\mathrm{N}=906)$} \\
\hline Kekele Polyclinic & 145 & 43.3 & 71 & 12.4 & 216 & 23.8 \\
\hline Pentecost Hospital & 190 & 56.7 & 500 & 87.6 & 690 & 76.2 \\
\hline \multicolumn{7}{|l|}{ Patient age-group } \\
\hline$<5$ & 186 & 24.7 & 963 & 54.5 & 1149 & 45.6 \\
\hline$\geq 5$ & 552 & 73.3 & 788 & 44.6 & 1340 & 53.2 \\
\hline Unknown & 15 & 2.0 & 15 & 0.9 & 30 & 1.2 \\
\hline \multicolumn{7}{|l|}{ Sex } \\
\hline Male & 343 & 45.6 & 848 & 48.0 & 1191 & 47.3 \\
\hline Female & 410 & 54.4 & 917 & 51.9 & 1327 & 52.7 \\
\hline \multicolumn{7}{|l|}{ Client on NHIS } \\
\hline Yes & 426 & 56.6 & 1026 & 58.1 & 1452 & 57.6 \\
\hline No & 327 & 43.4 & 740 & 41.9 & 1067 & 42.4 \\
\hline
\end{tabular}

ABBREVIATION: NHIS, national health insurance scheme; a: Proportion of those prescribed or not prescribed antibiotics; b: proportion based on total number seen in the municipal facility

The distribution of symptoms of the patients by age group is presented (Table 2a). A total of 11,953 symptoms were recorded. While headache $(10.5 \%)$ was generally the most frequently reported symptom, nasal congestion (11.6\%), poor appetite $(11.2 \%)$, cough $(10.3 \%)$ and watery stool $(8.4 \%)$ were more frequently reported among the children under 5 .

Table 2a: Distribution of symptoms by age-group 


\begin{tabular}{|c|c|c|c|c|c|c|c|}
\hline \multirow[t]{2}{*}{ Symptoms } & \multicolumn{7}{|c|}{ Age-group in years } \\
\hline & $\begin{array}{c}<5 \\
(n=1149)\end{array}$ & $\begin{array}{c}5-14 \\
(n=353)\end{array}$ & $\begin{array}{c}15-29 \\
(n=435)\end{array}$ & $\begin{array}{c}30-44 \\
(n=310)\end{array}$ & $\begin{array}{c}\geq 45 \\
(n=242)\end{array}$ & $\begin{array}{l}\text { Unknown } \\
(n=30)\end{array}$ & $\begin{array}{c}\text { Total } \\
(\mathrm{N}=2519)\end{array}$ \\
\hline Headache & $392(7.3)$ & 215 (12.7) & $289(13.1)$ & $201(14.3)$ & $\begin{array}{l}150 \\
(12.2)\end{array}$ & $11(12.0)$ & $1258(10.5)$ \\
\hline Poor appetite & $\begin{array}{l}600 \\
(11.2)\end{array}$ & $160(9.4)$ & $159(7.2)$ & $95(6.8)$ & $98(8.0)$ & $8(8.7)$ & $1120(9.4)$ \\
\hline $\begin{array}{l}\text { Nasal } \\
\text { congestion }\end{array}$ & $\begin{array}{l}619 \\
(11.6)\end{array}$ & $140(8.2)$ & $128(5.8)$ & $74(5.3)$ & $68(5.5)$ & $3(3.3)$ & $1032(8.6)$ \\
\hline $\begin{array}{l}\text { General Body } \\
\text { pains }\end{array}$ & $360(6.7)$ & $130(7.7)$ & 213 (9.7) & $152(10.9)$ & $\begin{array}{l}134 \\
(10.9)\end{array}$ & $6(6.5)$ & $995(8.3)$ \\
\hline Watery stool & $448(8.4)$ & $126(7.4)$ & $134(6.1)$ & $77(5.5)$ & $74(6.0)$ & $1(1.1)$ & $860(7.2)$ \\
\hline Dizziness & 356 (6.7) & $119(7.0)$ & $176(8.0)$ & $92(6.6)$ & $94(7.6)$ & $4(4.3)$ & $841(7.0)$ \\
\hline Cough & $\begin{array}{l}548 \\
(10.3)\end{array}$ & $94(5.5)$ & $70(3.2)$ & $57(4.1)$ & $47(3.8)$ & $12(13.0)$ & $828(6.9)$ \\
\hline Fatigue & 364 (6.8) & 107 (6.3) & $160(7.3)$ & $88(6.3)$ & $83(6.7)$ & $2(2.2)$ & $804(6.7)$ \\
\hline Dysuria & 366 (6.8) & $112(6.6)$ & $146(6.6)$ & $80(5.8)$ & $76(6.2)$ & $4(4.3)$ & $784(6.6)$ \\
\hline Nausea & 354 (6.6) & $105(6.2)$ & $136(6.2)$ & $72(5.2)$ & $79(6.4)$ & $1(1.1)$ & $747(6.2)$ \\
\hline Other & $\begin{array}{l}937 \\
(17.5)\end{array}$ & $389(22.9)$ & $588(26.7)$ & $403(29.0)$ & $\begin{array}{l}327 \\
(100.0)\end{array}$ & $40(43.5)$ & $2684(22.5)$ \\
\hline Total & $\begin{array}{l}5344 \\
(100.0)\end{array}$ & $\begin{array}{l}1697 \\
(100.0)\end{array}$ & $\begin{array}{l}2199 \\
(100.0)\end{array}$ & $\begin{array}{l}1391 \\
(100.0)\end{array}$ & $\begin{array}{l}1230 \\
(100.0)\end{array}$ & $92(100.0)$ & $\begin{array}{l}11953 \\
(100.0)\end{array}$ \\
\hline
\end{tabular}

Table $2 \mathrm{~b}$ shows the distribution of diagnoses by age group. On average, $4(10,026 / 2519)$ diagnoses were made per patient. Generally, the predominant diagnosis was ARTI (11.0\%). Among the under 5 age group, this pattern of ARTI being the most frequently diagnosed condition was observed (12.7\%). However, for all the other age groups, malaria was the most frequently diagnosed condition; $10.7 \%, 5-14$ years; $11.1 \%$, $15-29$ years; $10.4 \%, 30-44$ years; $10.4 \%, \geq 45$ years.

Table 2b: Distribution of diagnoses by age-group 


\begin{tabular}{|c|c|c|c|c|c|c|c|}
\hline \multirow[t]{2}{*}{ Diagnoses } & \multicolumn{7}{|c|}{ Age -group in years } \\
\hline & $\begin{array}{c}<5 \\
(n=1149)\end{array}$ & $\begin{array}{c}5-14 \\
(n=353)\end{array}$ & $\begin{array}{c}15-29 \\
(n=435)\end{array}$ & $\begin{array}{c}30-44 \\
(n=310)\end{array}$ & $\begin{array}{c}\geq 45 \\
(n=242)\end{array}$ & $\begin{array}{c}\text { Unknown } \\
(2=30)\end{array}$ & $\begin{array}{c}\text { Total } \\
(\mathrm{N}=2519)\end{array}$ \\
\hline ARTI & $618(12.7)$ & $136(9.4)$ & $157(9.5)$ & $101(9.8)$ & $85(8.6)$ & $9(22.0)$ & $1106(11.0)$ \\
\hline Malaria & $423(8.7)$ & $156(10.7)$ & $184(11.1)$ & $148(10.4)$ & $103(10.4)$ & $15(36.6)$ & $1029(10.3)$ \\
\hline UTI & 401 (8.3) & $119(8.2)$ & $143(8.6)$ & $81(7.8)$ & $71(7.2)$ & $4(9.8)$ & $819(8.2)$ \\
\hline $\begin{array}{l}\text { Typhoid } \\
\text { fever }\end{array}$ & $357(7.4)$ & $113(7.8)$ & $138(8.3)$ & $84(8.1)$ & $79(7.4)$ & $1(2.4)$ & $772(7.7)$ \\
\hline Enteritis & $371(7.7)$ & $122(8.4)$ & $127(7.7)$ & $72(7.0)$ & $73(7.4)$ & $1(2.4)$ & $766(7.6)$ \\
\hline Pneumonia & $379(7.8)$ & $103(7.1)$ & $117(7.1)$ & $65(6.3)$ & $68(6.8)$ & $0(0.0)$ & $732(7.3)$ \\
\hline $\begin{array}{l}\text { Ear } \\
\text { infection }\end{array}$ & $387(8.0)$ & $104(7.2)$ & $113(6.8)$ & $59(5.7)$ & $68(6.8)$ & $0(0.0)$ & 731 (7.3) \\
\hline Tonsilitis & $368(7.6)$ & $114(7.8)$ & $114(6.9)$ & $65(6.3)$ & $65(6.5)$ & $0(0.0)$ & $726(7.2)$ \\
\hline Anaemia & $344(7.1)$ & $109(7.5)$ & $122(7.4)$ & $70(6.8)$ & $67(6.7)$ & $3(7.3)$ & $715(7.1)$ \\
\hline $\begin{array}{l}\text { Eye } \\
\text { infection }\end{array}$ & $360(7.4)$ & $107(7.4)$ & $109(6.6)$ & $60(5.8)$ & $66(6.6)$ & $0(0.0)$ & $702(7.0)$ \\
\hline Others & $841(17.3)$ & $271(18.6)$ & $331(20.0)$ & $229(22.1)$ & $248(25.0)$ & $8(19.5)$ & $1928(19.2)$ \\
\hline Totals & $\begin{array}{l}4849 \\
(100.0)\end{array}$ & $\begin{array}{l}1454 \\
(100.0)\end{array}$ & $\begin{array}{l}1655 \\
(100.0)\end{array}$ & $\begin{array}{l}1034 \\
(100.0)\end{array}$ & $\begin{array}{l}993 \\
(100.0)\end{array}$ & $41(100.0)$ & $\begin{array}{l}10026 \\
(100.0)\end{array}$ \\
\hline
\end{tabular}

ABBREVIATION: ARTI, Acute Respiratory Tract Infection; UTI, Urinary Tract Infection

Table 3 presents a summary of the prescriber-patient interactions regarding antibiotics prescriptions at the health facilities during the period when the records were taken. Overall, the prevalence of antibiotics prescription was $70.1 \%$ (95\% Cl: $67.7 \%-72.4 \%$ ). Age-group stratified analyses showed that prevalence of antibiotic prescription was $83.8 \%$ (95\% Cl: 81.3-86.1) among patients under 5 and $58.8 \%$ (95\% Cl: $55.7-$ 61.9) among patients aged 5 years or more. Of the 1766 prescriptions that had antibiotics prescribed, approximately half (49.2\%) were written by physician assistants, $43.9 \%$ by medical doctors and $5.7 \%$ by nurse prescribers. Regarding the number of years they had been practising, $31.4 \%$ of the patients were seen by prescribers who had been practising for less than 3 years, a little over a third $(37.7 \%)$ had been practising for 3 to 5 years, and $30.9 \%$ had been practising for 6 years or more. The largest proportion of the prescriptions with antibiotics were written by prescribers who had been practising for 3 to 5 years (37.4\%). While $79.4 \%$ of the prescriptions with antibiotics were written by prescribers who had never been trained on integrated management of neonatal and childhood illnesses (IMNCI), 87.9\% of the prescriptions without antibiotics were written by those with no training on $\mathrm{IMNCl}$.

Medicines prescribed other than antibiotics included antimalarials, analgesics, haematinics, cough remedies, antacids. The proportion of those prescribed antimalarials was $54.2 \%(408 / 753)$ among those who were not prescribed antibiotics and $35.6 \%(628 / 1766)$ among those who were prescribed antibiotics.

\section{Table 3: Prescriber-patient interactions by antibiotics prescription}




\begin{tabular}{lllllll}
\hline \multirow{2}{*}{ Prescriber Characteristic } & \multicolumn{5}{c}{ Antibiotics prescription } \\
\cline { 2 - 7 } & Not prescribed & Prescribed & Total, $\mathbf{N}=\mathbf{2 5 1 9}$ \\
\hline \multirow{2}{*}{ Prescriber's Profession } & $\mathbf{n}$ & $\mathbf{\%}$ & $\mathbf{n}$ & $\mathbf{\%}$ & $\mathbf{n}$ & $\%$ \\
\hline Medical Doctor & & & & & & \\
\hline Physician Assistant & 439 & 38.4 & 776 & 43.9 & 1065 & 42.3 \\
\hline Nurse prescriber & 24 & 3.2 & 100 & 5.7 & 124 & 4.9 \\
\hline Other & 8 & 1.1 & 21 & 1.2 & 29 & 1.2 \\
\hline Total & 753 & 100.0 & 1766 & 100.0 & 2519 & 100.0 \\
\hline Prescriber's years of practice & & & & & & \\
\hline$<3$ & 279 & 37.7 & 500 & 28.7 & 779 & 31.4 \\
\hline $3-5$ & 284 & 38.4 & 652 & 37.4 & 936 & 37.7 \\
\hline $6-9$ & 99 & 13.4 & 289 & 16.6 & 388 & 15.7 \\
\hline$\geq 10$ & 78 & 10.5 & 300 & 17.2 & 378 & 15.2 \\
\hline Total & 740 & 100.0 & 1741 & 100.0 & 2481 & 100.0 \\
\hline Ever trained on IMNCI & & & & & & \\
\hline Yes & 91 & 12.1 & 363 & 20.6 & 454 & 18.0 \\
\hline No & 662 & 87.9 & 1403 & 79.4 & 2065 & 82.0 \\
\hline Total & 753 & 100.0 & 1766 & 100.0 & 2519 & 100.0 \\
\hline
\end{tabular}

IMNCI - Integrated management of childhood illnesses.

A total of 1109 (44.0\%) of patients were referred for laboratory investigations, 1007 (40.0\%) were tested for malaria, 909 (36.1\%) took the full blood count test, $9(0.4 \%)$ took the stool routine examination, and $146(5.8 \%)$ took the urine routine examination

Results of the multivariable logistic regression analyses (Table 4a) identified the following as significant non-clinical factors of antibiotic prescription: location of facility (municipality), age of patient and prescriber's professional category, years of practice, and training in IMNCl, Compared to prescribers who had practised for less than 3 years, those who had 6 to 9 years of practice experience and those who had practiced for 10 years or more had 3 times $(\mathrm{AOR}=2.97 ; 95 \% \mathrm{Cl}$ : 1.99-4.44) and 1.6 times (AOR = 1.60; $95 \% \mathrm{Cl}$ : 1.12-2.27) higher odds of prescribing antibiotics, respectively. Prescribers who had ever been trained on IMNCI had 2.3 times greater odds of prescribing antibiotics than those who had never been trained $(A O R=2.33 ; 95 \% \mathrm{Cl}: 1.54-3.53)$. After adjusting for all the other covariates, children aged 5 years or above were $60 \%(A O R=0.40 ; 95 \% \mathrm{Cl}$ : $0.32-0.51)$ less likely to be prescribed antibiotics than those under 5 .

Table 4a: Crude and adjusted logistic regression of factors associated with antibiotic prescribing 


\begin{tabular}{|c|c|c|c|c|}
\hline & Crude OR (95\% CI) & p-value & Adjusted OR (95\% CI) & p-value \\
\hline \multicolumn{2}{|c|}{ Prescriber's Profession (Ref: Medical Doctor) } & $0.001 * * *$ & & $0.029 *$ \\
\hline Physician Assistant & $0.75(0.60,0.94)$ & & $0.83(0.58,1.20)$ & \\
\hline Nurse Prescriber & $1.55(1.06,2.27)$ & & $1.30(0.70,2.41)$ & \\
\hline Other & $0.98(0.44,2.19)$ & & $8.33(1.32,52.41)$ & \\
\hline \multicolumn{2}{|c|}{ Prescriber's years of practice (Ref: $<3$ ) } & $<0.001 * * *$ & & $<0.001 * * *$ \\
\hline $3-5$ & $1.28(0.98,1.67)$ & & $1.12(0.84,1.48)$ & \\
\hline $6-9$ & $1.63(1.15,2.31)$ & & $2.97(1.99,4.44)$ & \\
\hline$\geq 10$ & $2.15(1.50,3.06)$ & & $1.60(1.12,2.27)$ & \\
\hline \multicolumn{2}{|c|}{ Prescriber ever trained on IMNCI (Ref: No) } & $<0.001 * * *$ & & $<0.001 * * *$ \\
\hline Yes & $1.88(1.38,2.56)$ & & $2.33(1.54,3.53)$ & \\
\hline \multicolumn{2}{|l|}{ Municipality (Ref: Ga South) } & $<0.001 * * *$ & & $<0.001 * * *$ \\
\hline La Dade Kotopon & $0.64(0.49,0.84)$ & & $0.16(0.09,0.27)$ & \\
\hline La Nkwantanang Madina & $1.17(0.89,1.54)$ & & $0.88(0.56,1.40)$ & \\
\hline \multicolumn{2}{|l|}{ Sex of patient (Ref: Male) } & 0.235 & & 0.627 \\
\hline Female & $0.90(0.77,1.07)$ & & $1.05(0.87,1.27)$ & \\
\hline \multicolumn{2}{|c|}{ Age of patient in years (Ref: $<5$ ) } & $<0.001 * * *$ & & $<0.001^{* * *}$ \\
\hline$\geq 5$ & $0.28(0.23,0.34)$ & & $0.40(0.32,0.51)$ & \\
\hline
\end{tabular}

$\mathrm{P}<0.05 *, \mathrm{p}<0.01^{* *}, \mathrm{p}<0.001^{* * *}$, significance levels; CI, Confidence Interval; OR, odds ratio; Ref, Reference.

The significant clinical factors as identified from the multivariable logistic regression (Table 4b) include laboratory investigation, symptoms including cough, dizziness, difficulty in swallowing, watery stool, and diagnoses including urinary tract infection, typhoid fever, and skin disease. Patients who presented with cough were 3.54 times more likely to be prescribed antibiotics than those who did not cough $(A O R=3.54$; $95 \% \mathrm{Cl}: 2.54-4.92)$. Patients for whom laboratory investigations were requested were $29 \%(A O R=0.71$; 95\% Cl: 0.57-0.89) less likely to be prescribed antibiotics than those for whom laboratory investigations were not requested. Sex of patient, symptoms including general body pains, nasal congestion and diagnoses including ARTI and pneumonia were not significant factors of antibiotic prescribing $(p<0.05)$.

Table 4b: Crude and adjusted logistic regression of factors associated with antibiotic prescribing 


\begin{tabular}{|c|c|c|c|c|}
\hline & Crude OR (95\% CI) & p-value & Adjusted OR (95\% CI) & p-value \\
\hline Cough (Ref: No) & & $<0.001 * * *$ & & $<0.001^{* * *}$ \\
\hline Yes & $3.28(2.57,4.19)$ & & $3.54(2.54,4.92)$ & \\
\hline Dizziness (Ref: No) & & $0.033^{*}$ & & $<0.001 * * *$ \\
\hline Yes & $0.81(0.66,0.98)$ & & $0.48(0.33,0.71)$ & \\
\hline Difficulty in swallowing (Ref: $\mathbf{N}$ & No) & $0.001 * *$ & & $<0.001^{* * *}$ \\
\hline Yes & $2.87(1.51,5.44)$ & & $7.78(3.43,17.64)$ & \\
\hline Watery stool (Ref: No) & & $0.044 *$ & & $0.031 *$ \\
\hline Yes & $1.24(1.01,1.53)$ & & $1.56(1.04,2.34)$ & \\
\hline General body pain (Ref: No) & & 0.019* & & 0.104 \\
\hline Yes & $0.79(0.65,0.96)$ & & $0.79(0.59,1.05)$ & \\
\hline Nasal congestion (Ref: No) & & $<0.001 * * *$ & & 0.11 \\
\hline Yes & $1.67(1.36,2.04)$ & & $1.30(0.94,1.80)$ & \\
\hline Laboratory investigations (Ref: & f: No) & $<0.001 * * *$ & & $0.003^{* *}$ \\
\hline Yes & $0.62(0.51,0.74)$ & & $0.71(0.57,0.89)$ & \\
\hline Pneumonia (Ref: No) & & $0.035 *$ & & 0.147 \\
\hline Yes & $1.27(1.02,1.60)$ & & $1.57(0.85,2.88)$ & \\
\hline Acute respiratory tract infectiol & on (Ref: No) & $<0.001 * * *$ & & 0.728 \\
\hline Yes & $1.80(1.44,2.25)$ & & $0.95(0.70,1.28)$ & \\
\hline Typhoid fever (Ref: No) & & $0.015 *$ & & $<0.001^{* * *}$ \\
\hline Yes & $1.32(1.06,1.66)$ & & $3.78(2.28,6.26)$ & \\
\hline Urinary tract infection (Ref: No & & $<0.001 * * *$ & & $<0.001 *$ \\
\hline Yes & $1.51(1.20,1.89)$ & & $3.53(2.23,5.60)$ & \\
\hline Skin disease (Ref: No) & & $0.02 *$ & & $0.020 *$ \\
\hline Yes & $1.54(1.07,2.20)$ & & $1.82(1.10,3.02)$ & \\
\hline
\end{tabular}

$\mathrm{P}<0.05 *, \mathrm{p}<0.01 * *, \mathrm{p}<0.001 * * *$, significance levels; CI, Confidence Interval; OR, odds ratio; Ref, Reference.

p>The most prevalent diagnosis among the patients was ARTI (Figure1). The diagnoses not found to be significantly associated with antibiotic prescription were malaria, diarrhoeal diseases, anaemia, ear infection, eye infection, enteritis, trauma and tonsillitis (Table $2 \mathrm{~b}$ ). The other diagnoses that were not included in the analyses include hypertension, bacteraemia, nephritis, mastitis, diabetes mellitus.

Diagnoses of interest: all diagnoses which had a prevalence of at least $5 \%$ in the database

Figure 1: Bar chart showing the prevalence of diagnoses of interest. ARTI, Acute Respiratory Tract Infection; UTI, Urinary Tract Infection

\section{Discussion}

We aimed to determine the factors associated with antibiotic prescription for febrile patients. The major factors identified were prescriber's profession and years of practice, age of patient, presenting symptoms 
including cough, watery stool, dizziness, difficulty in swallowing, laboratory tests, diagnoses including typhoid fever, urinary tract infection and skin disease.

A high prescription of antibiotics for febrile patients was observed. The prevalence of prescribing antibiotics, which was $70.1 \%$ (95\% Cl: 67.7-72.4) was higher than was found among febrile patients in Zambia [22]. An important difference observed between the 2 studies which could explain the difference in prevalence is that a higher proportion of the febrile patients $(74.6 \%)$ underwent diagnostic testing in the Zambian study than in the present study (44\%). Studies in Uganda [23] and Cameroon [24] have shown that laboratory testing reduces the odds of antibiotic prescribing. Indeed, our findings showed that when laboratory investigations were requested prior to prescribing, patients were less likely to be prescribed with antibiotics. This was observed although the laboratory tests requested did not include culture test or any non-malaria point-of-care testing for infections. Advocating for the increased use of point-of-care tests for infections could improve the control of antibiotic prescribing. Despite the scarcity of resources, it must be considered that the ultimate cost of overprescribing antibiotics outweighs the cost of the optimal use of laboratory services.

The prevalence of antibiotics prescription in our study is higher than has been reported by other studies in Ghana, and other developing countries [9,25]. A critical difference between our study and these other studies is that only febrile patients were included in the current study. This suggests that the prevalence of antibiotics prescription among the sub-population of febrile patients is higher than among the general population of patients. The higher use of antibiotics among febrile patients may not be justified since a majority of the infections targeted are mostly caused by viruses $[26,27]$.

Elsewhere, respiratory tract infection has been shown to be predictive of antibiotic prescription $[24,28,29]$. Other studies in Ghana also observed a high prescription of antibiotics for ARTI management at health facilities $[30,31,32]$. In this study, the observation that neither ARTI nor pneumonia is significantly associated with antibiotic prescribing seems progressive (Table $3 b$ ).

The finding in our study is suggestive of prescribers appreciating that these diseases are more likely to be caused by viruses rather than bacteria $[33,34]$ or that using antibiotics to treat these diseases provides no clear benefit $[35,36]$. This understanding may be translated to the treatment of febrile illnesses at large, since these principles apply generally but were not reflected in the findings. Cough is often associated with respiratory infection of one kind or the other. It seems paradoxical that it was found to be significantly associated with antibiotic prescribing whilst ARTI was not. Accordingly, a patient who presents with cough is likely to be prescribed an antibiotic, irrespective of whether ARTI or pneumonia is diagnosed. This raises the question of whether prescribers treat symptoms rather than the diseases they diagnose. Another related observation is that patients who present with watery stool are likely to be treated with antibiotics though same cannot be said when diarrhoea is diagnosed. Further studies are required to investigate this practice.

That prescribers with more than 5 years of practice experience are more likely to prescribe antibiotics than those with less experience is at variance with a study conducted in Italy [37] but similar to another 
study in Canada [38]. Our finding may be because of the fear medical doctors develop after a while of practice about their patients returning to them with similar symptoms following an initial visit $[21,39,40]$. Less experienced prescribers may uphold the seeming theoretical ideals of rational use of medicines, less encumbered by the practical challenges of inadequately treated diseases and the associated patient dissatisfaction. Over time, prescribers may prefer treating as many likely causes of a set of symptoms in the face of overwhelming workload, inadequate human resources and poorly resourced laboratories [41, 42]. It must be pointed out that at the time of the study, review of the STG was overdue by a year [43]. At instances of diagnosis uncertainty, more experienced prescribers may depend on their experience which may be more focused on the individual needs and expectations of their patients rather than the public health interest [40]. The prescribing practices of more experienced prescribers must be targeted by antibiotic stewardship interventions.

Though inadequate training of prescribers has been shown to worsen antibiotic prescribing [39] we found that those not trained on the IMNCl have lower odds of prescribing antibiotics. This appears to suggest that IMNCI training may be counterproductive for controlling high antibiotic prescribing. It is noteworthy that IMNCl is relevant in the management of childhood illnesses but our study included adults. That notwithstanding, it must be pointed out that one approach recommended by $\mathrm{IMNCl}$ is the active involvement of patients or caregivers in deciding on treatments [44]. This approach, however, has been suggested as influencing high antibiotic prescribing [45]. During IMNCI trainings, it may be necessary to point this out and address the tendency for higher use of antibiotics. Thus, integrating IMNCI training with responsible use of antibiotics may be worthwhile.

Regarding age, we found that patients aged 5 years or more had lower odds of being prescribed antibiotics. A similar observation was made in Cameroon [24]. Children under five, as a result of having less developed immune systems are more susceptible to infections than older people. As a result, prescribers are more likely to manage illnesses of children in this age group with antibiotics than in older age groups. Also, the higher rate of mortality among children under 5 may condition prescribers to prefer erring cautiously by prescribing antibiotics given that treatments are usually done empirically. This is occasioned by the resource constraints of the health facilities and relatively expensive diagnostic tests. This trend is worrying considering that high antibiotic consumption in childhood has been linked with the development of metabolic diseases in later life [46].

We conducted a literature search on PubMed and Google scholar, and to the best of our knowledge this is the largest study on antibiotics prescription in Ghana. The relatively large sample size allowed for the inclusion of several factors in the assessment. One limitation of this study is that the period of the data collection was short (3 months). As such, seasonal variations in antibiotics prescription was not accounted for. Another limitation of this study is the assumption that all documented actions were carried out. Similarly, all undocumented actions were assumed not to have been taken. This may have introduced misclassification bias but was considered more acceptable than direct observation which may have caused prescribers to vary their usual prescribing habit. Also, behavioural factors were not assessed. 


\section{Conclusion}

The factors associated with antibiotic prescription for febrile patients were prescriber's profession and years of practice; age of patient; some presenting symptoms which included cough, watery stool, dizziness, difficulty in swallowing, laboratory tests; some diagnoses including typhoid fever, urinary tract infection and skin disease. In contrast, ARTI and pneumonia were not significantly associated with antibiotic prescription.

The rate of antibiotics prescription for febrile patients is high. To reduce this, advocacy for the increased use of laboratory testing prior to prescribing antibiotics is key. Also, more experienced prescribers and treatment for children under five should be targeted with interventions aimed at reducing antibiotic prescribing. IMNCI training appears to be counterproductive for controlling antibiotic prescribing. There is the need to emphasize responsible use of antibiotics during IMNCI training.

\section{References}

1. World Health Organization. Interventions and strategies to improve the use of antimicrobials in developing countries: a review. 2001;:35.

2. Bell BG, Schellevis F, Stobberingh E, Goossens H, Pringle M. A systematic review and meta-analysis of the effects of antibiotic consumption on antibiotic resistance. BMC Infectious Diseases. 2014;14. doi:10.1186/1471-2334-14-13.

3. Klein EY, Van Boeckel TP, Martinez EM, Pant S, Gandra S, Levin SA, et al. Global increase and geographic convergence in antibiotic consumption between 2000 and 2015. Proceedings of the National Academy of Sciences. 2018;115:E3463-70.

4. European Centre for Disease Prevention and Control. Annual Epidemiological report for 2017 Antimicrobial consumption. 2017;:23.

5. World Health Organization. WHO Report on Surveillance of Antibiotic Consumption: 2016-2018 Early implementation. Geneva; 2018.

6. Vialle-Valentin CE, LeCates RF, Zhang F, Desta AT, Ross-Degnan D. Predictors of antibiotic use in African communities: evidence from medicines household surveys in five countries: Predictors of antibiotic use in African communities. Tropical Medicine \& International Health. 2012;17:211-22.

7. Ntšekhe M, Hoohlo-Khotle N, Tlali M, Tjipura D. Antibiotic Prescribing Patterns at Six Hospitals in Lesotho. 2011;:40.

8. Versporten A, Zarb P, Caniaux I, Gros M-F, Drapier N, Miller M, et al. Antimicrobial consumption and resistance in adult hospital inpatients in 53 countries: results of an internet-based global point prevalence survey. The Lancet Global Health. 2018;6:e619-29.

9. Labi A-K, Obeng-Nkrumah N, Nartey ET, Bjerrum S, Adu-Aryee NA, Ofori-Adjei YA, et al. Antibiotic use in a tertiary healthcare facility in Ghana: a point prevalence survey. Antimicrobial Resistance \& Infection Control. 2018;7. doi:10.1186/s13756-018-0299-z. 
10. Sumaila A-N, Tabong PT-N. Rational prescribing of antibiotics in children under 5 years with upper respiratory tract infections in Kintampo Municipal Hospital in Brong Ahafo Region of Ghana. BMC Research Notes. 2018;11. doi:10.1186/s13104-018-3542-z.

11. Asante KP, Boamah EA, Abdulai MA, Buabeng KO, Mahama E, Dzabeng F, et al. Knowledge of antibiotic resistance and antibiotic prescription practices among prescribers in the Brong Ahafo Region of Ghana; a cross-sectional study. BMC Health Services Research. 2017;17. doi:10.1186/s12913-017-2365-2.

12. Biezen R, Brijnath $B$, Grando D, Mazza D. Management of respiratory tract infections in young children-A qualitative study of primary care providers' perspectives. NPJ Prim Care Respir Med. 2017;27. doi:10.1038/s41533-017-0018-x.

13. Cabral C, Horwood J, Hay AD, Lucas PJ. How communication affects prescription decisions in consultations for acute illness in children: a systematic review and meta-ethnography. BMC Family Practice. 2014;15. doi:10.1186/1471-2296-15-63.

14. World Health Organization. WHO Global Strategy for Containment of Antimicrobial Resistance. 2001;:105.

15. Ministry of Health, Ministry of Food and Agriculture, Ministry of Environment, Science, Technology and Innovation, Ministry of Fisheries and Aquaculture Development. Policy on Antimicrobial Use and Resistance for Ghana. 1st edition. 2017.

16. Lopez-Vazquez P, Vazquez-Lago JM, Figueiras A. Misprescription of antibiotics in primary care: a critical systematic review of its determinants. Journal of Evaluation in Clinical Practice. 2012;18:473-84.

17. McDonagh MS, Peterson K, Winthrop K, Cantor A, Lazur BH, Buckley DI. Interventions to reduce inappropriate prescribing of antibiotics for acute respiratory tract infections: summary and update of a systematic review. J Int Med Res. 2018;46:3337-57.

18. Centre for Clinical Practice at NICE. National Institute for Health and Care Excellence: Clinical Guidelines. National Institute for Health and Care Excellence (UK); 2008.

19. Bonful HA. SMS Intervention and prescriber adherence to uncomplicated malaria case management guidelines in three municipalities in the Greater Accra Region of Ghana. University of Ghana; 2017. http://ugspace.ug.edu.gh/handle/123456789/25632.

20. StataCorp. Statistical Software: Release 14. College Station, TX: StataCorp LP; 2015.

21. WHO Collaborating Centre for Drug Statistics Methodology. Guidelines for ATC classification and DDD assignment 2013. Oslo; 2012.

22. Ndhlovu M, Nkhama E, Miller JM, Hamer DH. Antibiotic prescribing practices for patients with fever in the transition from presumptive treatment of malaria to 'confirm and treat' in Zambia: a crosssectional study. Tropical Medicine \& International Health. 2015;20:1696-706.

23. Batwala V, Magnussen P, Nuwaha F. Antibiotic use among patients with febrile illness in a low malaria endemicity setting in Uganda. Malar J. 2011;10:377. 
24. Chem ED, Anong DN, Akoachere J-FKT. Prescribing patterns and associated factors of antibiotic prescription in primary health care facilities of Kumbo East and Kumbo West Health Districts, North West Cameroon. PLOS ONE. 2018;13:e0193353.

25. Holloway KA, Ivanovska V, Wagner AK, Vialle-Valentin C, Ross-Degnan D. Have we improved use of medicines in developing and transitional countries and do we know how to? Two decades of evidence. Tropical Medicine \& International Health. 2013;18:656-64.

26. Malm K, Nyarko KM, Kenu E, Bart-Plange C, Koram KA, Gyapong JO, et al. Malaria and respiratory syncytial virus as causes of acute febrile illness in an urban paediatric population in Ghana. MWJ. 2014;5.

27. D'Acremont V, Kilowoko M, Kyungu E, Philipina S, Sangu W, Kahama-Maro J, et al. Beyond MalariaCauses of Fever in Outpatient Tanzanian Children. New England Journal of Medicine. 2014;370:809-17.

28. O'Brien K, Bellis TW, Kelson M, Hood K, Butler CC, Edwards A. Clinical predictors of antibiotic prescribing for acutely ill children in primary care: an observational study. $\mathrm{Br} \mathrm{J}$ Gen Pract. 2015;65:e585-592.

29. Anderson H, Vuillermin P, Jachno K, Allen KJ, Tang ML, Collier F, et al. Prevalence and determinants of antibiotic exposure in infants: A population-derived Australian birth cohort study: Antibiotic use in Australian infants. Journal of Paediatrics and Child Health. 2017;53:942-9.

30. Opoku MM. Assessment of Antibiotics Prescribing Practices at the Sunyani Municipal Hospital In 2015. Thesis. University of Ghana; 2017. http://ugspace.ug.edu.gh/handle/123456789/23711. Accessed 12 Nov 2019.

31. Duah NA. Prescription Practices and Patterns of Antibiotics used in Children Attending the Princess Marie Louise Children's Hospital. Thesis. University of Ghana; 2018. http://ugspace.ug.edu.gh/handle/123456789/25873. Accessed 12 Nov 2019.

32. Anamuah-Mensah M. A Survey of Antibiotic Usage at Holy Trinity Medical Centre. 2009. http://ir.knust.edu.gh:8080/handle/123456789/377. Accessed 12 Nov 2019.

33. Johnstone J, Majumdar SR, Fox JD, Marrie TJ. Viral Infection in Adults Hospitalized With Community-Acquired Pneumonia: Prevalence, Pathogens, and Presentation. CHEST. 2008;134:11418.

34. Marcos MA, Camps M, Pumarola T, Martinez JA, Martinez E, Mensa J, et al. The role of viruses in the aetiology of community- acquired pneumonia in adults. Antiviral Therapy. 2006;:9.

35. Woodhead M, Blasi F, Ewig S, Garau J, Huchon G, leven M, et al. Guidelines for the management of adult lower respiratory tract infections - Full version. Clinical Microbiology and Infection. 2011;17:E1-59.

36. Smucny J, Fahey T, Becker L, Glazier R. Antibiotics for acute bronchitis. Cochrane Database Syst Rev. 2004;:.CD000245.

37. Di Martino M, Lallo A, Kirchmayer U, Davoli M, Fusco D. Prevalence of antibiotic prescription in pediatric outpatients in Italy: the role of local health districts and primary care physicians in 
determining variation. A multilevel design for healthcare decision support. BMC Public Health. 2017;17. doi:10.1186/s12889-017-4905-4.

38. Cadieux G, Tamblyn R, Dauphinee D, Libman M. Predictors of inappropriate antibiotic prescribing among primary care physicians. Canadian Medical Association Journal. 2007;177:877-83.

39. Calbo E, Álvarez-Rocha L, Gudiol F, Pasquau J. A review of the factors influencing antimicrobial prescribing. Enfermedades Infecciosas y Microbiología Clínica. 2013;31:12-5.

40. Butler CC, Rollnick S, Pill R, Maggs-Rapport F, Stott N. Understanding the culture of prescribing: qualitative study of general practitioners' and patients' perceptions of antibiotics for sore throats. BMJ. 1998;317:637-42.

41. Pearson M, Doble A, Glogowski R, Ibezim S, Lazenby T, Haile-Redai A, et al. Antibiotic prescribing and resistance: Views from low- and middle-income prescribing and dispensing professionals. Report to World Health Organisation AMR Secretariat. 2018.

42. Ataiyero Y, Dyson J, Graham M. Barriers to hand hygiene practices among health care workers in subSaharan African countries: A narrative review. American Journal of Infection Control. 2018;0. doi:10.1016/j.ajic.2018.09.014.

43. Ministry of Health. Standard Treatment Guidelines 2010. 2010.

44. Victora CG, Adam T, Bryce J, Evans DB. Integrated Management of the Sick Child. In: Disease Control Priorities in Developing Countries. Second. Washington DC: The World Bank and Oxford University Press; 2006. p. 1177-92.

45. McKay R, Mah A, Law MR, McGrail K, Patrick DM. Systematic Review of Factors Associated with Antibiotic Prescribing for Respiratory Tract Infections. Antimicrobial Agents and Chemotherapy. 2016;60:4106-18.

46. Mensah KB, Ansah C. Irrational use of antibiotics and the risk of diabetes in Ghana. Ghana Med J. 2016;50:107-14.

\section{List Of Abbreviations}

ARTI-Acute Respiratory Tract Infection

EML-Essential Medicines List

IMNCl-Integrated Management of Neonatal and Childhood Illnesses

NHIS-National Health Insurance Scheme

OPD-Outpatient department

STG-Standard Treatment Guidelines

UTI-Urinary Tract Infection 


\section{Declarations}

\section{Ethics Approval and Consent to Participate}

Ethical approval for the primary study was given by the Ethics Review Committee of the Ghana Health Service. Permission was further sought from the Greater Accra Regional Health Administration, the Municipal Health directorates of the study sites and the management of Health facilities and prescribers. Informed consent were obtained from all the prescribers who saw the patients whose records were used.

\section{Consent for publication}

All medical superintendents of the six health facilities and the prescribers were adequately informed about the study and they consented to the publication of the research study findings. Adequate information about the original study was also placed at vantage points in all health facilities during the data collection period.

\section{Availability of Data and Material}

The dataset is not publicly available. However, it can be accessed after a reasonable request has been sent to the corresponding author.

\section{Competing Interests}

The authors declare that they have no competing interests.

\section{Funding}

Funding for the original study was obtained from the German Academic Exchange Service Project as part of funding for the PhD project of the corresponding author.

\section{Authors' Contributions}

$\mathrm{HAB}$ and $\mathrm{MMO}$ conceptualised the study under the supervision of KAK. HAB assisted MMO in the analysis phase. Interpretation was done by MMO, HAB and KAK. All the authors reviewed and approved the final manuscript for publication. 


\section{Acknowledgements}

We would like to acknowledge Dr. Adolf Kofi Awua of Ghana Atomic Energy Commission and Prof. Kwame Ohene Buabeng of the Faculty of Pharmacy and Pharmaceutical Sciences, Kwame Nkrumah University of Science and Technology for reviewing and proof reading the manuscript.

\section{Figures}

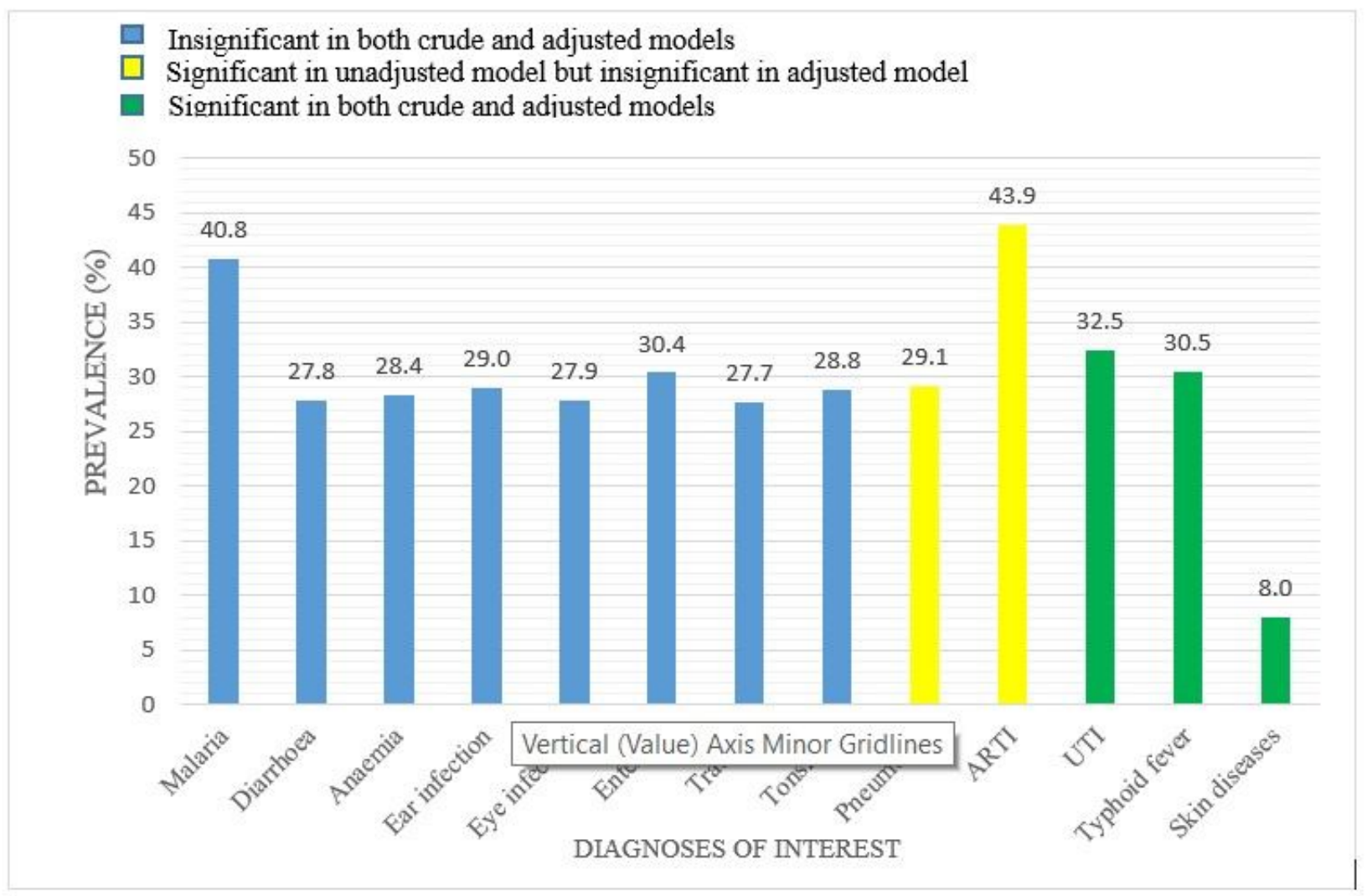

Figure 1: Bar chart showing the prevalence of diagnoses of interest. ARTI, Acute Respiratory Tract Infection; UTI, Urinary Tract Infection

\section{Figure 1}

\section{Supplementary Files}

This is a list of supplementary files associated with this preprint. Click to download.

- Tables.docx 